increased CRP (OR: 0.922 [0.854-0.995; $\mathrm{P}=0.036]$ were significantly less likely to reach a PsAID score $<4$.

Abstract AB0778 Table 1.. Demographic and clinical characteristics of PsA patients with PsAID $<4$

\begin{tabular}{|c|c|}
\hline & $\begin{array}{c}\text { Total } \\
\mathrm{N}(122)\end{array}$ \\
\hline Male, n (\%) & $70(57.4)$ \\
\hline Age, mean (SD), yr & $54.5(12.7)$ \\
\hline BMI, mean (SD) $\left(\mathrm{kg} / \mathrm{m}^{2}\right)$ & $27.1(3.9)$ \\
\hline CRP (mg/L), mean (SD) & $2.8(3.3)$ \\
\hline \multicolumn{2}{|l|}{ Comorbidities, n (\%) } \\
\hline Dyslipidemia & $40(32.8)$ \\
\hline $\mathrm{HBP}$ & $33(27.0)$ \\
\hline Obesity & $30(24.6)$ \\
\hline DM & $12(9.8)$ \\
\hline \multicolumn{2}{|l|}{ PsA clinical patterns, $n(\%)$} \\
\hline Axial & $3(2.5)$ \\
\hline Peripheral & $107(87.7)$ \\
\hline Mixed & $12(9.8)$ \\
\hline DIP disease & $45(36.9)$ \\
\hline \multicolumn{2}{|l|}{ Familial history, $\mathrm{n}(\%)$} \\
\hline Psoriasis & $60(49.2)$ \\
\hline PsA & $11(9.0)$ \\
\hline Ankylosing spondylitis & $2(1.6)$ \\
\hline PsA duration, mean (SD), yrs. & $9.6(7.9)$ \\
\hline Skin symptoms duration, mean (SD), yrs. & $21.6(14.5)$ \\
\hline Articular symptoms duration, mean (SD), yrs. & $11.9(8.7)$ \\
\hline \multicolumn{2}{|l|}{ Radiologic findings } \\
\hline Erosions in hands, $\mathrm{n}(\%)$ & $40(32.8)$ \\
\hline Erosions in feet, $\mathrm{n}(\%)$ & $33(27.0)$ \\
\hline PASI, mean (SD) & $1.2(3.8)$ \\
\hline $\mathrm{HAQ}$, mean (SD) & $0.2(0.3)$ \\
\hline $\mathrm{HAQ} \leq 0.5, \mathrm{n}(\%)$ & $104(85.2)$ \\
\hline MDA, n (\%) & $76(62.3)$ \\
\hline Kappa $\left[\mathrm{Cl}_{95 \%}\right] \mathrm{HAQ} \leq 0.5$ vs. PsAID $<4$ & $0.5325[0.4212-0.6438]$ \\
\hline Kappa $\left[\mathrm{Cl}_{95 \%}\right]$ MDA vs. PsAID $<4$ & $0.3594[0,2393-0,4795]$ \\
\hline
\end{tabular}

MDA; Minimal disease activity; SD: Standard deviation; BMI: Body mass Index. CRP: CReactive Protein; HBP: High blood pressure; DIP: distal interphalangeal joint disease. DM: Diabetes mellitus; PASI: Psoriasis Area and Severity Index; HAQ: Health Assessment Questionnaire; PsAID: Psoriatic Arthritis Impact of Disease. $\mathrm{Cl}$ : confidence intervals

Conclusion: There are discrepancies between the treatment goals (MDA) and the impact of disease as assessed by PSAID. Clinical characteristics such as DIP involvement, inflammatory load (PCR) and genetic factors (familial history) seem to be associated with a lower probability of being in an acceptable symptoms state in PsA patients.

Disclosure of Interests: Rubén Queiró Silva: None declared, Juan D. Cañete: None declared, Susana Gómez Employee of: I am a current employee of Pfizer., Ana Cabez Employee of: Pfizer

DOI: 10.1136/annrheumdis-2019-eular.4232

\section{AB0779 TOWARDS A GLOBAL MANAGEMENT OF PSORIATIC ARTHRITIS: ESTIMATION OF THE CARDIOVASCULAR RISK AND THE ACTIVITY OF THE DISEASE IN CLINICAL PRACTICE}

José Andrés Lorenzo Martín ${ }^{1}$, Estefania Pardo Campo ${ }^{2}$, Marina Pino Martínez ${ }^{1}$, Lilian Consuelo Charca Benavente ${ }^{1}$, Luis Marcelino Arboleya Rodríguez ${ }^{1}$, Sara Alonso Castro ${ }^{1}$, Mercedes Alperi-López ${ }^{1}$, Francisco Javier Ballina-García ${ }^{1}$, Rubén Queiró Silva ${ }^{1} .{ }^{1}$ Hospital Universitario Central de Asturias, Oviedo, Spain; ${ }^{1}$ Hospital Universitario Central de Asturias, Oviedo, Spain

Background: Psoriatic arthritis (PsA) patients usually have a high prevalence of cardiovascular risk factors (CVRF) and cardiovascular events, which makes the routine estimation of cardiovascular risk (CVR) highly advisable. Currently, this risk is estimated through classic risk scores (SCORE, Framinghan), however, the values of these scores may underestimate the real CVR of these patients.

On the other hand, in clinical decision making and when evaluating the therapeutic response, it is advisable the use of some composite activity index. The heterogeneity of PsA makes it difficult to estimate the real activity and the remission state, so it is important to assess which of these composite index is more suitable for these purposes in clinical practice.

Objectives: We aimed to analyze whether carotid ultrasound is a useful tool for estimating CVR in patients with PsA, and if it is capable of correcting the estimated risk using classical tables. We also analyzed the usefulness of the MDA criteria and the DAPSA categories for clinical decision making in real practice.
Methods: A cross-sectional study was conducted with 136 consecutive patients with PSA (CASPAR criteria). Sociodemographic and anthropometric data, CVRF, disease activity according to DAPSA categories, HAQ, MDA, and CVR measured by SCORE chart, was collected. An IMT> 800 $\mu \mathrm{m}$ and/or the presence of carotid plaque (Mannheim consensus), defined a high CVR by ultrasound. We analyzed the concordance (kappa) between the MDA response and the low activity and remission categories according to the DAPSA. Clinical variables of PsA associated with a high CVR were evaluated by multivariateanalyses.

Results: Intima-media thickness values correlated well with CVR categories according to SCORE ( $p<0.0001) .40 \%$ of patients included in the low and moderate risk categories according to the SCORE risk chart were reclassified as high CVR after the ultrasound examination.

\begin{tabular}{lccc}
\hline & \multicolumn{3}{c}{ High cardiovascular risk (ultrasound) } \\
\hline & $\begin{array}{c}\text { No } \\
\mathbf{n}(\%)\end{array}$ & $\begin{array}{c}\text { Yes } \\
\mathbf{n}(\%)\end{array}$ & $\mathbf{p}$ value \\
\hline SCORE risk chart & $51(87.9)$ & $7(12.1)$ & $<0.0005$ \\
Low & $35(71.4)$ & $14(28.6)$ & \\
Moderate & $11(39.3)$ & $17(60.7)$ & \\
High & & & \\
\hline
\end{tabular}

In the multivariate analysis, some characteristics of the disease were independently associated with a high CVR.

\begin{tabular}{lcc} 
& OR (95\% Cl) & $\begin{array}{c}\mathbf{p} \\
\text { value }\end{array}$ \\
\hline Age & $1.08(1.03-1.13)$ & 0.00 \\
HAQ & $1.94(0.68-5.56)$ & 0.22 \\
DM & $1.65(0.42-6.40)$ & 0.47 \\
AHT & $0.75(0.24-2.31)$ & 0.62 \\
DL & $2.61(0.91-7.48)$ & 0.07 \\
Tobacco & $4.26(1.44-$ & 0.01 \\
& $12.65)$ & \\
Enthesitis & $3.76(1.36-$ & 0.01 \\
& $10.40)$ & 0.02 \\
Erosions & $5.23(1.33-$ & \\
& $20.53)$ &
\end{tabular}

This reveals that patients with enthesitis and/or structural damage are those who tend to have a high CVR.

When comparing DAPSA and MDA criteria, we found a moderate correlation between the MDA response and the DAPSA low activity $(\kappa=0.52, p$ $<0.0001)$ and between MDA and DAPSA remission $(\kappa=0.47 ; p<0.0001)$. Conclusion: A high percentage of patients with low-moderate risk according to the SCORE risk chart are reclassified as patients with high CVR after the ultrasound examination.

The high CVR in our population is related not only to classical CVRF but also to the inflammatory load (enthesitis) and structural damage (erosions) of PsA.

DAPSA is an appropriate instrument for clinical decision making in routine practice because it correlates reasonably well with stringent therapeutic goals such as MDA.

Disclosure of Interests: None declared

DOI: 10.1136/annrheumdis-2019-eular.4794

\section{AB0780 PERSISTENCE OF MOLL AND WRIGHT CLASSIFICATION CRITERIA OVER TIME}

John Roberts IV ${ }^{1}$,Lisa A. Mandl ${ }^{2}$, Sergio Schwartzman $2 .{ }^{1}$ Hospital for Special Surgery, Rheumatology, New York, United States of America; ${ }^{2}$ Hospital for Special Surgery/Weill Cornell Medicine, Rheumatology, New York, United States of America

Background: In 1973 Moll and Wright published the first paper on the classification criteria for Psoriatic Arthritis (PsA) which included several phenotypes of PsA: Oligoarticular, Polyarticular, Axial, DIP, and Mutilans. Whether these subtypes change over time or are related to treatment response is not known. The hypothesis of this study is that with some exceptions, the Moll and Wright subtype classification criteria are stable over time and the pattern may have important therapeutic implications.

Objectives: The objective of this study was to evaluate the persistence of the Moll and Wright classification criteria in PsA patients.

Methods: This study is a retrospective chart review of PsA patients seen at a single center between January 1,2013 and December 31, 2016. The patients in this study were identified using the ICD-9 or ICD-10 codes for PsA and were then classified using the CASPAR classification criteria for psoriatic arthritis. Patients who met CASPAR classification 